\title{
Toward intercultural competency in multicultural marketplaces
}

Demangeot, C. , Adkins, N. , Mueller, R.D. , Henderson, G.R. , Ferguson, N. , Mandiberg, J. , Roy, A. , Johnson, G. , Kipnis, E. , Pullig, C. , Broderick, A. and Zuniga, M.

Published version deposited in CURVE May 2014

Original citation \& hyperlink:

Demangeot, C. , Adkins, N. , Mueller, R.D. , Henderson, G.R. , Ferguson, N. , Mandiberg, J. , Roy, A. , Johnson, G. , Kipnis, E. , Pullig, C. , Broderick, A. and Zuniga, M. (2013) Toward intercultural competency in multicultural marketplaces. Journal of Public Policy and Marketing, volume 32 (Special issue May 2013): 156-164.

http://dx.doi.org/10.1509/jppm.12.051

Publisher statement: (C 2013, American Marketing Association.

Copyright $(\subset$ and Moral Rights are retained by the author(s) and/ or other copyright owners. A copy can be downloaded for personal non-commercial research or study, without prior permission or charge. This item cannot be reproduced or quoted extensively from without first obtaining permission in writing from the copyright holder(s). The content must not be changed in any way or sold commercially in any format or medium without the formal permission of the copyright holders.

CURVE is the Institutional Repository for Coventry University http://curve.coventry.ac.uk/open 


\title{
Toward Intercultural Competency in Multicultural Marketplaces
}

\author{
Catherine Demangeot, Natalie Ross Adkins, \\ Rene Dentiste Mueller, Geraldine Rosa Henderson, \\ Nakeisha S. Ferguson, James M. Mandiberg, Abhijit Roy, \\ Guillaume D. Johnson, Eva Kipnis, Chris Pullig, \\ Amanda J. Broderick, and Miguel Angel Zúñiga
}

\begin{abstract}
Intercultural competency plays a pivotal role in creating a more equitable and just marketplace in which situations of marketplace vulnerability are minimized and resilience is enhanced. Intercultural competency is the ability to understand, adapt, and accommodate another's culture. In this essay, the authors present a framework of intercultural competency development in multicultural marketplaces. They discuss resilience-building actions for multicultural marketplace actors, specifically, consumers, companies/marketers, community groups and nongovernmental organizations, and policy makers for three phases of intercultural competency development.
\end{abstract}

Keywords: multicultural, marketplace, vulnerability, diversity, intercultural

\begin{abstract}
Catherine Demangeot is Lecturer of Marketing, University of Strathclyde (e-mail: catherine.demangeot@strath.ac.uk). Natalie Ross Adkins is Associate Professor of Marketing, College of Business and Public Administration, Drake University (e-mail: natalie.adkins@drake. edu). Rene Dentiste Mueller is Associate Dean of Undergraduate Studies and Professor of Marketing, School of Business, College of Charleston (e-mail: muellerr@cofc.edu). Geraldine Rosa Henderson is Associate Professor of Supply Chain Management and Marketing Sciences, Rutgers Business School, Rutgers University (e-mail: geraldine.henderson@rutgers.edu). Nakeisha S. Ferguson is Assistant Professor of Marketing, Opus College of Business, University of St. Thomas (e-mail: nsferguson@stthomas.edu). James M. Mandiberg is Assistant Professor of Management and Social Enterprise, School of Social Work, Columbia University (e-mail: jmm2151@columbia.edu). Abhijit Roy is Professor of Marketing, Kania School of Management, University of Scranton (e-mail: abhijit.roy@scranton.edu). Guillaume D. Johnson is Associate Researcher, Dauphine Recherche en Management, Université Paris-Dauphine (e-mail: guillaume.johnson@ gmail.com). Eva Kipnis is Senior Lecturer in Marketing, Coventry Business School, Coventry University (e-mail: yeva.kipnis2@coventry. ac.uk). Chris Pullig is Associate Professor and Chair of Marketing, Hankamer School of Business, Baylor University (e-mail: chris pullig@baylor.edu). Amanda J. Broderick is Dean and Chair in Marketing, Salford Business School, University of Salford (e-mail: a.j. broderick@salford.ac.uk). Miguel Angel Zúñiga is Assistant Professor of Marketing, Morgan State University (e-mail: migzungtz@yahoo. com). The authors acknowledge the 2011 Transformative Consumer Research conference, at Baylor University (June 24-26, 2011), whose Multicultural Marketplaces track discussions provided the initial impetus for this article. They thank the two anonymous JPP\&M referees for their comments and suggestions during the development of this essay. Stacy Baker served as guest editor for this article.
\end{abstract}

$\mathbf{T}$ The period following World War II has witnessed significant political, legislative, and social change, most notably, a concerted human rights initiative spearheaded by the United Nations and its member states. Adopted in 1948, the Universal Declaration of Human Rights affirms "universal respect for human rights and fundamental freedoms, including the principles of non-discrimination and civil and political rights, as well as social, cultural and economic rights" (United Nations 1998). This action not only influenced many legislative initiatives, such as the Civil Rights Act in the United States, but also stimulated business efforts to increase diversity and inclusion of difference in business environments initially through revised human resources hiring policies. The long evolution of workplace practices and legislation over the past 60 years has progressively turned the issue of diversity into a business case.

Today, many Fortune 500 companies have formalized comprehensive sets of strategies, policies, and success standards for workplace diversity and inclusion that stress the influence of diversity on outcomes including innovation, internationalization, employee satisfaction, productivity and organizational resilience (Reinmoeller and Van Baardwijk 2005). An increasing number of companies also work with diversity organizations and create specific affinity groups to imbue their employment, community engagement, and marketplace engagement strategies with a "diversity perspective." More recently, companies have adopted a broader, more modern conceptualization of diversity that focuses on the myriad ways that people differ and how those differences affect the organizations' activities (Carrell, Mann, and Sigler 2006). While workplace diversity continues to garner significant attention in both academic research and popular press accounts, considerably less attention to and recognition of marketplace diversity and inclusion activities currently exists. 
As marketplaces around the world become increasingly multicultural, the issue of marketplace diversity and inclusion brings to the fore the need for stakeholders to address marketplace practices that impede consumers from exercising their universal economic, social, and cultural rights without "distinction of any kind, such as race, color, sex, language, religion, political or other opinion, national or social origin, property, birth or other status" (United Nations 1948).

In the modern, global economy, the marketplace is culturally diverse; not only do consumers and merchants often come from diverse cultural backgrounds, but marketplace actors also encounter culturally different market practices and consumer expectations. These differences may cause tensions that unwittingly increase the potential occurrences of consumer vulnerability; that is, "a state of powerlessness arising from an imbalance in marketplace interactions or from the consumption of marketing messages and products" (Baker, Gentry, and Rittenburg 2005, p. 134). These differences may present physical, cognitive, social, or cultural barriers to access for the consumer and thereby jeopardize the realization of economic, social, and cultural rights “" indispensable' for his or her dignity and free and full personal development" (United Nations 1998). Multicultural marketplace tension may also affect the well-being of business employees, such as when consumers display unacceptable behavior toward immigrant shopkeepers (Johnson, Meyers, and Williams 2013 [in this issue]).

In multicultural marketplaces, which may include people from diverse ethnic groups, religious groups, or nationalities or groups that share common disabilities, sexual orientations, or beliefs, firms face the prospect of negatively affecting their reputation through the mismanagement of marketplace interactions and the alienation of consumers. However, firms could gain much trust, respect, and consumer loyalty from multicultural consumers if they successfully develop proactive strategies toward cultural inclusion. In addition, resilience during periods of changing markets, consumers, and practices positively affects companies' profits, future activities, employee welfare, and abilities to meet consumer needs (Hamel and Välikangas 2003).

In this essay, we propose a framework for marketplace actors (consumers, companies/marketers, community groups/nongovernmental organizations [NGOs], and policy makers) to work toward developing intercultural competency in multicultural marketplaces. Intercultural competency is the ability to understand, adapt to, and accommodate another's culture (Hammer 2009). We begin by further defining the core concepts and assumptions of multiculturalism and diversity, marketplace vulnerability, resilience, and intercultural competency. Next, we draw from the literature on consumer vulnerability (Baker and Mason 2012) and consumer discrimination (Williams et al. 2008) to articulate key steps along the path toward intercultural competency.

\section{Core Concepts and Key Assumptions}

\section{Multiculturalism and Diversity}

Traditional definitions of multiculturalism focus narrowly on identities related to a national or ethnic group or culture, while definitions of diversity focus on differences based on the categories of race, color, religion, sex, and national origin (Carrell, Mann, and Sigler 2006). Evolving definitions of multicultural consumers, however, build from broader conceptualizations of culture (Broderick et al. 2011a; Craig and Douglas 2006). Similarly, modern conceptualizations of diversity consider the myriad ways that people differ and how those differences affect organizations. Research shows that employing narrow definitions of diversity carries adverse effects to organizations, whereas broader conceptualizations help those in the majority "see how diversity honors individual differences including their own" (Carrell, Mann, and Sigler 2006, p. 6). We adopt the broader conceptualizations of multiculturalism and diversity. Accordingly, multicultural marketplaces include consumers from diverse ethnic groups, religious groups, or nationalities; people living in particular geographic regions; or groups that share common physical/mental disabilities, sexual orientation, beliefs, values, attitudes, or way of life (Friedman, LopezPumarejo, and Friedman 2007). Consistent with Article 1 of the United Nations Universal Declaration of Human Rights (1948), human beings are born free and equal in dignity and rights; multiculturalism and diversity help create a more equitable and just world (United Nations 1998) and thus serve as aspirational characteristics for marketplace structures and processes worldwide.

\section{Marketplace Vulnerability}

The preponderance of marketing research on vulnerability examines consumers who encounter situations in which they are at risk for harm or unfair treatment. Some research highlights the plight of consumers who share specific sociodemographic characteristics that deviate from the characteristics shared by the majority population, such as advanced age (the elderly), limited education (e.g., youth and adults without postsecondary education), limited language skills, female gender, racial and ethnic group affiliation, immigrant status, limited financial resources, access constrained by physical location, and physical and mental disabilities (Bristor, Lee, and Hunt 1995; Commuri and Ekici 2008; Hill 1995; Hill and Dhanda 1999; Jae 2009; Moschis, Mosteller, and Fatt 2011; Peñaloza 1995). Recent work in the field has supported a sociocultural conceptualization of vulnerability, in which factors including individual characteristics, identity states, and environmental factors such as elements of the community and context combine to produce situations in which vulnerability may be experienced (Adkins and Jae 2010; Adkins and Ozanne 2005; Baker, Gentry, and Rittenburg 2005; Baker and Mason 2012). ${ }^{1}$ The sociocultural nature of vulnerability suggests that (1) different people may react differently to the same situation (Broderick et al. 2011b; Kipnis et al. 2012; Shultz and Holbrook 2009), (2) virtually everyone is likely to experience situational or temporary vulnerability at some point in their lives (Baker, Gentry, and Rittenburg 2005; Mansfield and Pinto 2008), (3) people are likely to experience low levels of vulnerability in some situations and high levels of

\footnotetext{
1For an excellent review and comparison of the various approaches applied in vulnerability analyses, see Baker and Mason (2012).
} 
vulnerability in others (Shultz and Holbrook 2009), and (4) vulnerability in the marketplace is largely an emergent phenomenon in a complex world full of numerous cultures and value systems (Adkins and Jae 2010).

Several social and cultural factors work to disempower marketplace actors and create vulnerability in multicultural marketplaces (Baker and Mason 2012). For example, actors in multicultural marketplaces likely bring to the marketplace a variety of cultural identities (Kipnis et al. 2012) that form the basis of in-group and out-group comparisons (Tajfel and Turner 1979). ${ }^{2}$ People more identifiable as outsiders are more likely to be targets of prejudice and discrimination, thereby limiting their opportunities for adaptation and inclusion (Padilla and Perez 2003). This is especially true of stigmatized groups (Mandiberg and Warner 2012). Lack of access to social, cultural, and economic resources also compounds vulnerability (Lee, Ozanne, and Hill 1999; Shultz and Holbrook 2009). Consumers are not the only marketplace actors to experience instances of vulnerability and increased chance of harm in today's global economy. Companies, organizations, and even policies may become vulnerable when threats in the marketplace and environment attack organizational and policy weaknesses. Vulnerability in the marketplace will never be totally eliminated; however, it can be reduced and managed more effectively.

\section{Resilience}

Resilience, the ability to bounce back from adversity, is important for marketplace actors (Baker 2009). With regard to consumers, vulnerability induces resilient behaviors in which consumers and communities "transform their material, social, or ecological environments to reduce the negative impact and/or improve their quality of life" (Baker and Mason 2012, p. 550); resilient consumers survive and often thrive despite marketplace imbalances.

Companies exhibiting strategic resilience possess an "ability to dynamically reinvent business models and strategies as circumstances change, to continuously anticipate and adjust to changes that threaten their core earning power-and to change before the need becomes desperately obvious" (Hamel and Välikangas 2003, p. 52, emphasis in original). Resilient organizations monitor their environments, diversify resources and strategies, and take advantage of strategic windows.

At the core, resilience in multicultural marketplaces implies the continuous pursuit of goals, whether they consist of purchasing a desired item, achieving a high level of customer satisfaction, or providing a fair and equitable market structure for all. It is important to note that resilience does not necessarily translate into short-term successes but rather increases the probability of long-term success. Resilient marketplace actors enact prescriptive and preventative behaviors to minimize the severity and frequency of future instances of marketplace vulnerability.

2For more information about vulnerabilities encountered in the multicultural marketplace, see Broderick and her colleagues' work (Broderick et al. 2011a, b; Kipnis et al. 2012).

\section{Intercultural Competency}

"Intercultural competency" refers to the ability to successfully communicate with people of other cultures. Dominant theoretical models of intercultural competency across domains focus on three dimensions-cognition, affect, and behavior (Lloyd and Härtel 2010)-making intercultural competency conceptually similar to an attitude. From a cognitive perspective, to exhibit intercultural competency means that a person has the ability to perceive and interpret information about a culture other than his or her own; from an affective perspective, it involves appropriate feelings, attitudes, and traits necessary to successfully interact with culturally different others; and from a behavioral perspective, it suggests that a person has the competencies and abilities to communicate effectively in cross-cultural interactions. However, rather than being an end-state destination, intercultural competency is an ongoing process: marketplace actors become culturally competent rather than are competent (Campinha-Bacote 2002). Thus, actors in multicultural marketplaces exist at various stages of intercultural competency development.

\section{Theoretical Underpinnings}

Baker and Mason (2012) argue for a process model of consumer vulnerability and resilience in which micro and macro pressures interact with trigger events to give rise to vulnerability characterized by a lack of personal control and powerlessness. When situations of vulnerability occur in the marketplace, the affected person(s) must depend on external factors to respond and create or restore fairness in the marketplace (Baker, Gentry, and Rittenburg 2005; Baker and Mason 2012). A state of vulnerability taxes available individual resources and stimulates resilient behaviors. Resilience can be built when marketplace actors-consumers, companies/marketers, community groups and NGOs, and policy makers - work together toward the goal of fair and equitable treatment in the marketplace without discrimination, or, at the very least, toward the goal of reducing harm (Kipnis et al. 2012).

In their expanded model of consumer vulnerability, Adkins and Jae (2010) note that instances of vulnerability produce reactions from both consumers and the other marketplace actors. Consumers may react passively and accept their powerlessness, or they can actively resist the constraints they face (Adkins and Jae 2010; Adkins and Ozanne 2005). In contrast, other marketplace actors' reaction to instances of vulnerability largely depends on the frequency and severity of the occurrences and outcomes. For example, the American Disabilities Act resulted in part from the frequent struggles for access people with disabilities faced in public environments. Lack of access severely constrained a large number of people with disabilities. In contrast, no formal action may result from a consumer complaint about an employee giving poor service. Responses of various marketplace actors affect the way consumers respond; together, these consequences of vulnerability become antecedents to future 
interactions in which a risk of vulnerability exists (Adkins and Jae 2010).

Several researchers (Adkins and Corus 2009; Lee, Ozanne, and Hill 1999; Shultz and Holbrook 2009) have drawn from Bourdieu's (1977) theories to describe vulnerability in terms of marketplace imbalances arising as a result of unequal access to economic, social, and cultural resources. Economic capital (e.g., financial assets) is the most exchangeable. Social capital, which arises from group membership and access to social networks, enables members to leverage group cohesion and relationship ties. Cultural capital (which is associated with having learned, over time, the knowledge, linguistic competencies, preferences, and skills that give a person higher status in society) is the most important, and deficiencies in it constitute a major determinant of vulnerability (Bourdieu 1977; Shultz and Holbrook 2009). Both social and cultural forms of capital are necessary for intercultural competency.

In addition, in their work on consumer racial profiling, Williams et al. (2008) introduce the power-responsibility equilibrium framework, which offers some helpful insight into consumers' and policy holders' (identified as both firms and regulatory entities) responses to instances of vulnerability. They suggest the more powerful partner in a marketplace interaction holds a "societal obligation to ensure an environment of trust and confidence" (Williams et al. 2008, p. 180). Consumers experiencing instances of vulnerability lack power in the situation (Baker and Mason 2012), and to restore equilibrium to the interaction, they typically respond in one of three ways: exit, voice, or lost loyalty (Harris, Henderson, and Williams 2005; Hirschman 1970). In essence, consumers draw on their social and cultural capital in efforts to restore balance of power in the marketplace interaction.

Identity, social capital, and cultural capital are typically viewed as individual properties, which may roll up to the collective level through individual-collective interactions (Muñiz and O'Guinn 2001). These interactions can be viewed as properties of the collective that benefit or harm people. This is especially important for stigmatized collective identities that often lead to market exclusion (Mandiberg and Warner 2012). Forms of identity-based collective discrimination may lead some to reject their identity but may also lead to strengthening collective identity and bonds with others who share that identity (Padilla and Perez 2003). Strengthened identity often occurs through collective action such as seeking direct mainstream inclusion for all who share the identity and seeking inclusion through enhancing the otherness of the collective identity (Ogbu 2004).

In general, the efficacy of society and the marketplace is facilitated by the development of social capital (Crockett et al. 2011; Putnam 1993). Social capital is also instrumental in helping prevent, channel, or recover from conflicts and tensions arising within multicultural interactions (Colletta and Cullen 2000). Understandably, these conflicts and tensions likely trigger situations of vulnerability. Increasing social and cultural capital through the development of intercultural competency helps actors in multicultural marketplaces reduce the occurrence of marketplace vulnerability.

\section{A Multi-Stakeholder Framework Toward Intercultural Competency Development}

Intercultural competency plays a pivotal role in creating a more equitable and just world. Multicultural marketplace actors demonstrate resilient behaviors in response to and in anticipation of manifestations of marketplace vulnerability. As intercultural competency increases, the types of resilience-building actions change from more prescriptiveand thus reactive - to more preventive. Due to the evolving nature of intercultural competency, the framework contains three phases. We briefly discuss recommended actions for multicultural marketplace actors next. Figure 1 presents a summary of the resilience-building behaviors of multicultural marketplace actors in each phase of intercultural competency development.

\section{Phase 1: Discovery (Beginning)}

In the initial phase of intercultural competency development, marketplace actors largely respond to or recover from instances of marketplace vulnerability. Because these instances may not result in actual harm being done, multicultural marketplace actors may not be readily aware of some vulnerable situations; however, their responses to these situations do aid in building resilience for future interactions.

Because many experiences of vulnerability involve mundane, everyday purchases, little attention is paid when consumers are either denied the ability to purchase or provided with denigrated service; injustices frequently fail to surpass the required severity level to warrant additional action. However, on an aggregate basis (either individually or collectively), these everyday injustices promote stress that ultimately compromises physical and mental well-being. Moreover, what a person learns to accept in the realm of mundane consumption can carry over when the stakes are higher (e.g., large-ticket purchases, medical treatment). Therefore, during this first phase, multicultural marketplace actors should primarily focus on two types of actions: (1) coping with marketplace vulnerability and (2) reporting and educating appropriate stakeholders about experiences of heightened vulnerability and harm.

First, consumers in Phase 1 likely depend on social capital in the form of shopping helpers (Adkins and Corus 2009) or cultural capital in the form of consumer literacy (Adkins and Ozanne 2005) to navigate the complex multicultural marketplace. Broderick et al. (2011b) provide a detailed discussion of identity management techniques that leverage available capital resources in the multicultural marketplace. With regard to the second type of action, the power-responsibility equilibrium framework (Williams et al. 2008) suggests that consumers who experience situations of vulnerability in the multicultural marketplace exit the situation, voice their concerns, or complete the transaction with the possibility of future loss of loyalty; consequently, consumers should be encouraged to voice perceived vulnerability and/or harm they encounter to other stakeholders. Internally, voice could be to the actual offending marketplace actor or to someone up the chain of command. Externally, voice could be to the 
Figure 1. Resilience Building Actions: Phases of Intercultural Competency Development

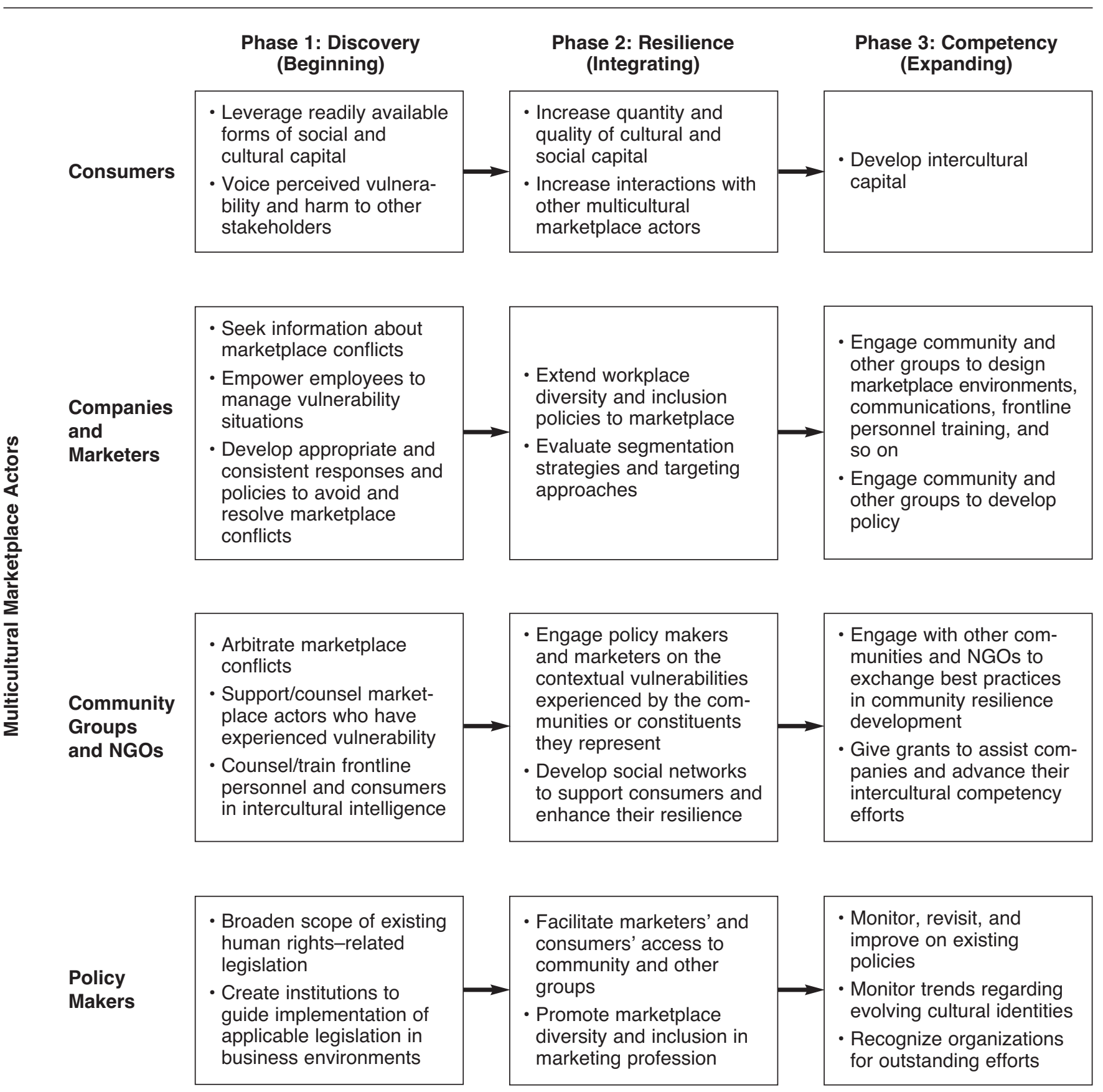

media, others (potential customers) through word-of-mouth or social media outlets, or to judicial, legislative, or regulatory entities.

Firms in the beginning stages of intercultural competency development should gather information about conflicts in the marketplace arising from differing cultural practices and beliefs. By providing consumers and employees a feedback mechanism on what elements in the marketplace worked well and what elements did not, companies can achieve higher levels of customer satisfaction and empower their employees to effectively resolve instances in the multicultural marketplace when harm has transpired. Some companies that recognize the complexity of multicultural marketplaces tackle the issue of potentially contentious consumerservice personnel interactions by leveraging the diversity in their workplace. For example, the hotel group Jumairah makes it a practice to match guests with an employee of similar nationality to handle inquiries.

Community groups and NGOs play an integral role in conveying information about and resilience toward mar- 
ketplace vulnerability. Several watchdog organizations exist to monitor marketplace activities to ensure fair treatment for all in the marketplace. Many times, these community groups and NGOs exercise great vigilance regarding the identification of heightened instances of vulnerability and discrimination; thus, they can often succeed in efforts to change or discontinue potentially harmful practices before harm occurs. Due to the advocacy nature and NGO status of many of these groups, they are uniquely qualified to arbitrate marketplace conflicts, support/counsel people who have experienced vulnerability, and provide intercultural or diversity education and training to multiple stakeholders.

Finally, policy makers should take action in the beginning stages of intercultural competency development. It is important to signal to society in general and to other stakeholders specifically that marketplace discrimination is unacceptable. One possible way to communicate this message is to broaden the scope of existing regulations and laws pertaining to human rights such as the Civil Rights Act and the American Disabilities Act in the United States. Currently, civil rights laws apply under two loose conditions: situations involving public areas and the ability to make and enforce contracts. Unfortunately, many situations leading to alleged marketplace discrimination do not fall under either one of the two conditions. Through an extension of appropriate legislative actions to encompass multicultural marketplace vulnerability situations, policy makers could compel relevant stakeholders to work toward intercultural competency and equitable access for all cultural groups. In addition, policy makers might be compelled to create institutions charged with adjudicating implementation of human rights legislation within the business environment.

\section{Phase 2: Resilience (Integrating)}

As intercultural competency continues to develop, multicultural marketplace actors are called to assimilate intercultural knowledge, skills, and experiences into practices and strategies. For consumers, this means a deliberate intent to broaden perspectives and increase the quantity and quality of cultural and social capital they possess. In terms of social capital, consumers need to learn to leverage bonds and commonalities shared with other multicultural marketplace actors. To broaden their perspectives, consumers should engage in interactions with multicultural marketplace actors from differing cultural backgrounds.

Phase 2 actions for business in general and marketers in particular should focus on extending workplace diversity and inclusion policies to marketplace activities. Tremendous synergy, which gives companies the ability to both do good and do well (Du, Bhattacharya, and Sen 2011), exists between workplace diversity and marketplace diversity. At this stage, companies understand that to be truly resilient in the modern, global economy, their workforce, manufacturing processes, product offerings, and marketing practices must reflect the entire world rather than isolated segments of it. Firms may choose to explicitly reach out to a broader marketplace in hopes of gaining allegiance from growing minority groups (Du, Bhattacharya, and Sen 2011). How- ever, firms should carefully consider the segmentation and targeting strategies employed (Ringold 1995; Smith and Cooper-Martin 1997): whereas target marketing is generally viewed as positive, profiling, intentionally or not, conveys exclusion. In multicultural marketplaces, segmenting can be a double-edged sword as the social identities of multicultural marketplace actors are becoming increasingly complex (Broderick et al. 2011a).

Community groups and NGOs may assume a training or collaboration role with various multicultural marketplace actors. Many groups routinely partner with firms to develop inclusive policies and procedures. For example, many organizations hold annual conferences to bring together representatives from the community, the government, other firms, and consumer groups to discuss the ways the multicultural marketplace might grow and thrive. Proactively, community groups can support individual consumers in their quest to improve marketplace experiences by providing educational programs and access to peer or community groups. From a reactive standpoint, organizations such as the National Association for the Advancement of Colored People and/or the American Civil Liberties Union help victims of marketplace discrimination identify and pursue remediation.

Enforcing an extended scope of legislative actions to encompass multicultural marketplaces would require collaboration between various stakeholders including public policy makers. Policy makers should develop programs to encourage companies to behave in proactive ways toward intercultural competency development and include intercultural competency-friendly approaches in their business practices.

\section{Phase 3: Competency (Expanding)}

At higher levels of intercultural competency development, the actions of multicultural marketplace actors epitomize strategic resilience: proactive, focused, and expansive (Hamel and Välikangas 2003). Actors draw on their expanding comprehension of multiculturalism and diversity when making decisions about marketplace activities. They seek best practices and continuous improvement by learning from one another.

Consumers in Phase 3 continue to acquire the intercultural capital to facilitate movement throughout various multicultural marketplaces. Through increased knowledge, skills, desire, and experiences in multicultural environments, they develop a sophisticated understanding and appreciation of various multicultural marketplace actors. They demonstrate an openness to engage in marketplace interactions, and they draw on their reservoir of strategies to transform situations of vulnerability to those of empowerment.

To design inclusive marketplace engagements, companies at this stage should leverage relationships with community groups and other NGOs. Issues of marketplace access, market space design, and marketplace interaction can be resolved with input from partners within the community. Multicultural inclusion takes many forms from using appropriate flesh-tones to providing for dietary and religious restrictions to communicating in a variety of languages. Community groups and organizations can help educate firms on the components and expectations of interculturally competent marketplace interactions. 
When marketers engage community and other groups to develop policy, they acknowledge the existence and value of cultural competency residing within communities associated with constituent groups. Partnerships and collaborations result in win-win scenarios by ensuring that the cultural rights and needs of the resident communities are intertwined with the marketers' business needs and are embedded in the design of new services, facilities, products, or communication. By involving the different communities within the catchment area during the design process of a new shopping mall, the mall's owners can design facilities that meet the needs and routines of the different communities (e.g., prayer rooms, ablution rooms, family restrooms, signage in different languages, the provision of a variety of eating facility layouts to cater to widely different party sizes) and attract tenants who understand the cultural rights, needs, and preferences of the communities they will serve, thus minimizing of risks of vulnerability and potentially gaining a competitive edge. All multicultural marketplace actors at this phase continuously monitor the global marketplace environment and seek ways to improve policies and practices to achieve intercultural competence in multicultural marketplaces.

\section{Discussion and Future Directions}

In this essay, we outline the necessary actions of multiple stakeholders to create an inclusive and equitable marketplace environment characterized by increasing levels of intercultural competency. However, the manner in which inclusion may be promoted varies between contexts. In certain countries, societal and legal norms dictate that the focus should be on the homogeneity of the marketplace rather than on its diversity. In those contexts, highlighting cultural differences through, for example, marketing strategies engenders important debates because it seems to threaten the national unity and nation building. This situation is particularly salient in countries where integration of immigrant minorities and discrimination against different cultural groups have become major political issues. Kipnis et al. (2012) offer insight into promoting marketplace inclusion in more hostile sociopolitical environments, but more research in this area is needed.

In this essay, we present a framework of resilience-building actions across three phases of intercultural competency development in multicultural marketplaces; however, the question of accurately determining the knowledge, attitudes, and skills that constitute intercultural competency in multicultural marketplaces remains. While several intercultural competency instruments currently exist, their applicability to and validity in the marketplace environment require empirical exploration. Furthermore, research is needed to identify markers signaling the transition between the various phases of intercultural competency development for each of the marketplace actors.

While some literature has addressed the remedial side of vulnerabilities related to cross-cultural contact (e.g., Yoo, Matsumoto, and LeRoux 2006) and focuses on individuals, fewer studies have considered the preventive side, which is mostly the remit of other stakeholders. Thus, we contribute to this literature by offering a framework illustrating how multiple multicultural marketplace actors exhibit resilience and move toward the elimination, anticipation, and/or mediation of marketplace vulnerability. The framework highlights the important role of social and cultural capital in the development of an interculturally competent marketplace.

We extend the work of Williams et al. (2008) and Baker and Mason (2012). We broaden the scope of the powerresponsibility equilibrium framework by applying it to all multicultural groups dealing with marketplace discrimination rather than focusing solely on race. The framework is applicable across all domains of marketplace interactions. We highlight the roles of community groups and NGOs in the process of building higher levels of capital among their constituencies and leveraging capital across groups and situations. Finally, whereas both Williams et al. (2008) and Baker and Mason (2012) establish marketplace dynamics that may lead to vulnerabilities and instances of resilience building, we propose specific actions that multicultural marketplace actors should collectively take to ensure that all consumers can pursue their universal economic, social, and cultural rights in the marketplace.

The need for additional research on preventive and prescriptive solutions to thwart marketplace vulnerability and further advance the business case of diversity is critical in the multicultural marketplace of the twenty-first century global economy. We challenge our colleagues to continue our quest for intercultural competency.

\section{References}

Adkins, Natalie Ross and Canan Corus (2009), "Health Literacy for Improved Health Outcomes: Effective Capital in the Marketplace," Journal of Consumer Affairs, 43 (2), 199-222.

_ and Haeran Jae (2010), "Marketplace Vulnerability of Limited English Proficient Consumers: Opportunities to Increase Knowledge in Macromarketing," Journal of Macromarketing, 30 (1), 93-104.

— and Julie L. Ozanne (2005), "The Low-Literate Consumer," Journal of Consumer Research, 32 (1), 93-105.

Baker, Stacey Menzel (2009), "Vulnerability and Resilience in Natural Disasters: A Marketing and Public Policy Perspective," Journal of Public Policy \& Marketing, 28 (Spring), 114-23.

—_ James W. Gentry, and Terri L. Rittenburg (2005), "Building Understanding of the Domain of Consumer Vulnerability," Journal of Macromarketing, 25 (2), 1-12.

and Marlys Mason (2012), "Toward a Process of Consumer Vulnerability and Resilience: Illuminating Its Transformative Potential," in Transformative Consumer Research: for Personal and Collective Well-Being, David Glen Mick, Simone Pettigrew, Cornelia Pechmann, and Julie L. Ozanne, eds. New York: Routledge, 543-61.

Bourdieu, Pierre (1977), Outline to a Theory of Practice. Cambridge, UK: Cambridge University Press.

Bristor, Julia M., Renee Gravois Lee, and Michelle R. Hunt (1995), "Race and Ideology: African-American Images in Television Advertising," Journal of Public Policy \& Marketing, 14 (Spring), 48-59.

Broderick, Amanda J., Catherine Demangeot, Natalie Ross Adkins, Nakeisa S. Ferguson, Geraldine Rosa Henderson, Guillaume Johnson, et al. (2011b), "Consumer Empowerment in 
Multicultural Marketplaces: Navigating Multicultural Identities to Reduce Consumer Vulnerability," Journal of Research for Consumers, 19 (January), 1-13.

, Eva Kipnis, Miguél Zuñiga, Abhijit Roy, Chris Pullig, et al. (2011a), "No Harm Done? Culture-Based Brandings and Its Impact on Consumer Vulnerability: A Research Agenda," Social Business, 1 (3), 263-80.

Campinha-Bacote, Josepha (2002), "The Process of Cultural Competence in the Delivery of Health Care Services: A Model of Care," Journal of Transcultural Nursing, 13 (3), 181-84.

Carrell, Michael R., Everett E. Mann, and Tracey Honeycutt Sigler (2006), "Defining Workplace Diversity Programs and Practices in Organizations: A Longitudinal Study," Labor Law Journal, 57 (1), 5-12.

Colletta, Nat and Michelle Cullen (2000), Violent Conflict and the Transformation of Social Capital: Lessons from Cambodia, Rwanda, Guatemala, and Somalia. Washington, DC: The World Bank.

Commuri, Suraj and Ahmet Ekici (2008), "An Enlargement of the Notion of Consumer Vulnerability," Journal of Macromarketing, 28 (2), 183-86.

Craig, C. Samuel and Susan P. Douglas (2006), "Beyond National Culture: Implication for Cultural Dynamics for Consumer Research," International Marketing Review, 23 (3), 322-42.

Crockett, David, Laurel Anderson, Sterling A. Bone, Abhijit Roy, Jeff Jianfeng Wang, and Garrett Coble (2011), "Immigration, Culture, and Ethnicity in Transformative Consumer Research," Journal of Public Policy \& Marketing, 30 (Spring), 47-54.

Du, Shuili, C.B. Bhattacharya, and Sankar Sen (2011), "Corporate Social Responsibility and Competitive Advantage: Overcoming the Trust Barrier," Management Science, 57 (9), 1528-45.

Friedman, Hershey H., Tomas Lopez-Pumarejo, and Linda Weiser Friedman (2007), "Frontiers in Multicultural Marketing: The Disabilities Market," Journal of International Marketing and Marketing Research, 32 (1), 25-39.

Hamel, Gary and Lïsa Välikangas (2003), "The Quest for Resilience," Harvard Business Review, 81 (9), 52-63.

Hammer, Mitchell R. (2009), “The Intercultural Development Inventory (IDI): An Approach for Assessing and Building Intercultural Competence," in Contemporary Leadership and Intercultural Competence: Exploring The Cross-Cultural Dynamics within Organizations, M.A. Moodian, ed. Thousand Oaks, CA: Sage Publications, 203-217.

Harris, Anne-Marie G., Geraldine R. Henderson, and Jerome D. Williams (2005), "Courting Customers: Assessing Consumer Racial Profiling and Other Marketplace Discrimination," Journal of Public Policy \& Marketing, 24 (Spring), 163-71.

Hill, Ronald Paul (1995), "Researching Sensitive Topics in Marketing: The Special Case of Vulnerable Populations," Journal of Public Policy \& Marketing, 14 (Spring), 143-48.

— and Kanwalroop Kathy Dhanda (1999), "Gender Inequity and Quality of Life: A Macromarketing Perspective," Journal of Macromarketing, 19 (2), 140-52.

Hirschman, Albert O. (1970), Exit, Voice, and Loyalty. Cambridge, MA: Harvard University Press.

Jae, Haeran (2009), "Linguistically Isolated Consumers: Historical Trends and Vulnerability in the U.S. Marketplace," Marketing Management Journal, 19 (2), 72-83.
Johnson, Guillaume D., Yuvay J. Meyers, and Jerome D. Williams (2013), "Immigrants Versus Nationals: When an Intercultural Service Encounter Failure Turns to Verbal Confrontation," Journal of Public Policy \& Marketing, 32 (Special Issue), $38-47$.

Kipnis, Eva, Amanda J. Broderick, Catherine Demangeot, Natalie Ross Adkins, Nakeisha S. Ferguson, Geraldine Rosa Henderson, et al. (2012), "Branding Beyond Prejudice: Navigating Multicultural Marketplaces for Consumer Well-Being," Journal of Business Research, (published electronically August 30), [DOI:10.1016/j.jbusres.2012.08.011].

Lee, Renee G., Julie L. Ozanne, and Ronald Paul Hill (1999), "Improving Service Encounters Through Resource Sensitivity: The Case of Health Care Delivery in an Appalachian Community," Journal of Public Policy \& Marketing, 18 (Fall), 230-48.

Lloyd, Shannon and Charmine Härtel (2010), "Intercultural Competencies for Culturally Diverse Work Teams," Journal of Managerial Psychology, 25 (8), 845-75.

Mandiberg, James M. and Richard Warner (2012), "Business Development and Marketing Within Communities of Social Service Clients," Journal of Business Research, (published electronically), [DOI:10.1016/j.jbusres.2012.02.015]

Mansfield, Phylis M. and Mary Beth Pinto (2008), "Consumer Vulnerability and Credit Card Knowledge Among Developmentally Disabled Citizens," Journal of Consumer Affairs, 42 (3), 425-38.

Mochis, George P., Jill Mosteller, and Choong Kwai Fatt (2011), "Research Frontiers on Older Consumers' Vulnerability," Journal of Consumer Affairs, 45 (3), 467-91.

Muñiz, Albert M., Jr., and Thomas C. O'Guinn (2001), "Brand Community," Journal of Consumer Research, 27 (4), 412-32.

Ogbu, John U. (2004), "Collective Identity and the Burden of 'Acting White' in Black History, Community, and Education," The Urban Review, 36 (1), 1-35.

Padilla, Amado M. and William Perez (2003), "Acculturation, Social Identity, and Social Cognition: A New Perspective," Hispanic Journal of Behavioral Sciences, 25 (1), 35-55.

Peñaloza, Lisa (1995), "Immigrant Consumers: Marketing and Public Policy Considerations in the Global Economy," Journal of Public Policy \& Marketing, 14 (Spring), 83-94.

Putnam, Robert D. (1993), "The Prosperous Community: Social Capital and Public Life," The American Prospect, 13 (Spring), $35-42$.

Reinmoeller, Patrick and Nicole van Baardwijk (2005), "The Link Between Diversity and Resilience," MIT Sloan Management Review, 46 (4), 61-65.

Ringold, Debra Jones (1995), "Social Criticisms of Target Marketing," American Behavioral Scientist, 38 (4), 578-92.

Shultz, Clifford J. and Morris B. Holbrook (2009), "The Paradoxical Relationship Between Marketing and Vulnerability," Journal of Public Policy \& Marketing, 28 (Spring), 124-27.

Smith, Craig N. and Elizabeth Cooper-Martin (1997), "Ethics and Target Marketing: The Role of Product Harm and Consumer Vulnerability," Journal of Marketing, 61 (July), 1-20.

Tajfel, Henri and John Turner (1979), "An Integrative Theory of Intergroup Conflict," in The Social Psychology of Intergroup Relations, William G. Austin and Stephen Worchel, eds. Monterrey, CA: Brooks-Cole, 94-109. 
United Nations (1948), "The Universal Declaration of Human Rights," (accessed June 7, 2012), [available at http://www. un.org/en/documents/udhr/].

(1998), "A United Nations Priority: Universal Declaration of Human Rights," (accessed June 21, 2012), [available at http://www .in.org/rights/HRToday/declar.htm].

Williams, Jerome D., May O. Lwin, Anne-Marie Hakstian, and Velma Gooding (2008), "Assessing Perceived Discrimination in 'Brick and Mortar' Retail Settings Using a Power-Responsi- bility Equilibrium Framework," in Brick \& Mortar Shopping in the 21 st Century, Tina M. Lowrey, ed. Mahwah, NJ: Lawrence Erlbaum Associates, 172-79.

Yoo, Seung-Hee, David Matsumoto, and Jeffrey A. LeRoux (2006), "The Influence of Emotion Recognition and Emotion Regulation on Intercultural Adjustment," International Journal of Intercultural Relations, 30 (3), 345-63. 
Copyright of Journal of Public Policy \& Marketing is the property of American Marketing Association and its content may not be copied or emailed to multiple sites or posted to a listserv without the copyright holder's express written permission. However, users may print, download, or email articles for individual use. 